\title{
Effect of Photoperiod Manipulation on Spawning Time and Performance of Turbot (Scophthalmus maximus)
}

\author{
Hamza Polat $^{1}$ (D), Rafet Cagri Ozturk ${ }^{2, *}$ (D), Yahya Terzi ${ }^{2}$ (D) Ilhan Aydin ${ }^{3}$ (D) Ercan Kucuk $^{1}$ iD \\ ${ }^{1}$ Central Fisheries Research Institute, Trabzon, Turkey \\ ${ }^{2}$ Karadeniz Technical University, Faculty of Marine Sciences, Department of Fisheries Technology Engineering, Trabzon, \\ Turkey \\ ${ }^{3}$ General Directorate of Agricultural Research and Policies-TAGEM, Ankara, Turkey
}

How to cite

Polat, H., Ozturk, R.C., Terzi, Y., Aydin, I., Kucuk, E. (2021). Effect of Photoperiod Manipulation on Spawning Time and Performance of Turbot (Scophthalmus maximus). Aquaculture Studies, 21, 109-115. http://doi.org/10.4194/2618-6381-v21_3_03

\section{Article History}

Received 10 January 2021

Accepted 03 March 2021

First Online 13 March 2021

\section{Corresponding Author}

Tel.: +904623778059

E-mail: rafetcagriozturk@gmail.com

\section{Keywords}

Turbot

Photoperiod

Spawning time

Spawning performance

\begin{abstract}
Temperature and photoperiod are known as the main stimuli of seasonal reproduction in fish. Turbot (Scophthalmus maximus) is a spring spawning teleost fish species with a promising aquaculture potential and high market value. This study was conducted to assess the effect of photoperiod manipulation on spawning time and spawning performance of turbot. A total of 28 mature turbots from the Black Sea population were subjected to manipulated photoperiod (a photoperiod regime that fish would naturally receive three months later) and natural photoperiod for almost a year. While the fish exposed to natural photoperiod spawned in May, the fish exposed to manipulated photoperiod spawned almost three months earlier compared to the natural photoperiod group. Reproductive and hatchery performance of the manipulated photoperiod and natural photoperiod groups were similar. It can be emphasized that photoperiod play an important role in accelerating maturation and spawning. The findings of this study could be implemented in the turbot aquaculture industry to advance production.
\end{abstract}

\section{Introduction}

Turbot, Scophthalmus maximus, is an economically important demersal fish species that widely distributed in the northeastern Atlantic Ocean, the Baltic Sea, the Mediterranean Sea, and the Black Sea (Firidin et al., 2020). Turbot spawns during the early summer from April to June in the Black Sea (Aydin et al., 2020; Aydin \& Şahin, 2011), from March to May in the Adriatic Sea (Caputo et al., 2001), and from May to August in the North Sea (Jones, 1974) which coincides with several environmental factors. The variability of the spawning season is considered as a result of an evolutionary adaptation to various environments with different environmental conditions to maximize reproductive success and to guarantee the maximum survival of the offspring. The development of gametes is a complex multifactorial process. Like most of the fish species, turbot exhibit a seasonal cycle in the production of gametes. Various strategies are being implemented to manipulate the spawning time of the fish. Environmental cues, such as water temperature cycles and photoperiod are two of the most important spawning stimuli in temperate fish species (Akhoundian et al., 2020; Altinok et al., 2020; Bromage et al., 2001; Oliveira et al., 2011).

Changes in photoperiod are mainly responsible for controlling the oocyte growth (Hansen et al., 1992), maturation (Imsland et al., 1997), and spawning time (Akhoundian et al., 2020). Imsland et al. (1995) and Turker (2005) assessed the effect of the photoperiod on growth of $S$. maximus and reported that the extended light period promotes the growth. Imsland et al. (2013) revealed that continuous light in long-term delays maturity in turbot whereas 16 hours light and 8 hours dark promotes growth and maturation. Turbot juveniles subjected to extended photoperiod resulted in faster growth compared to the fish reared at natural 
photoperiod (Imsland \& Jonassen, 2003). The effect of modification in photoperiod on spawning time is well documented in numerous fish species including sea bass (Dicentrarchus labrax) (Carrillo et al., 1989), zebrafish (Danio rerio) (Abdollahpour et al., 2020), rainbow trout (Oncorhynchus mykiss) (Bromage et al., 1984), and Nile tilapia (Oreochromis niloticus) (Kilincceker \& Kurt, 2010). To the best of our knowledge, no previous study has investigated the effect of photoperiod on the spawning time of turbot. In the present study, i) the effect of photoperiod manipulation on spawning time and ii) the effect of advanced spawning on sperm quality, egg quality, fertilization rate was assessed.

\section{Material and Method}

\section{Fish and experimental design}

The photoperiod manipulation experiment was conducted at the Central Fisheries Research Institute, Trabzon-Turkey. Turbot, S. maximus, used in the present study was originated from the Black Sea turbot population. To determine the influence of the photoperiod on the seasonal reproduction cycle of turbot, experimental group fish were exposed to manipulated photoperiod (MP group) and natural photoperiod (NP group) from June $1^{\text {st }}$ until the reproduction season. Up to this date, the fish were reared on natural photoperiod. If the natural photoperiod cycle was continued all the fish were expected to be ready to spawn in May. MP group was exposed to the photoperiod regime that they would normally receive three months later. For instance, in June, MP group fish were subjected to the photoperiod regime that they would normally receive in September.

Mature 8-year-old turbots were randomly assigned to each group. Fourteen turbot, 7 females $(57.76 \pm 1.35$ $\mathrm{cm}, 4470.51 \pm 336.03 \mathrm{~g})$ and 7 males $(54.47 \pm 0.87 \mathrm{~cm}$, $3198.18 \pm 467.08 \mathrm{~g})$, were assigned to the NP group while another fourteen turbot, 7 females $(59.11 \pm 1.34 \mathrm{~cm}$, $4683.60 \pm 155.2 \mathrm{~g})$ and 7 males $(56.20 \pm 1.05 \mathrm{~cm}$, $3252.22 \pm 172.4 \mathrm{~g})$, were assigned to the MP group. Fish were tagged with passive integrated transponder (PIT) tags (Digital Angel Corporation, USA). Two $20 \mathrm{~m}^{3}$ octagonal concrete tanks (one for each group) with 15 $\mathrm{m}^{2}$ of base area supplied with flow-through seawater were used in the experiments. Seawater taken from the depth of 40 meters with natural water temperature was continuously pumped to the system and the water exchange rate was set as 1000\% (10 times a day) in each tank.

The tank of the MP group was isolated with lightproof sheets and illuminated by an artificial led light source, mounted 1.5 meters above the water surface. Light intensity on the water surface was set as 60 lux using bulbs (Philips, 80W, Natural White Light: 40004500K). Automated time clocks were adjusted weekly during the experiments to adjust the daylength. Natural photoperiod and manipulated photoperiod regimes are given in Figure 1.

During the experiments, fish were fed once a day by hand to apparent satiation with red mullet, whiting, and anchovy. Water temperature was measured twice a day while salinity, $\mathrm{pH}$, and dissolved oxygen concentrations were measured weekly (Figure 2). Water quality parameters were nearly identical in both tanks throughout the study.

\section{Gamete collection, hormone injection, and spawning}

The oocyte maturity stage was assessed from a sample of oocytes cannulated from the ovaries of females using a cannula. Oocytes were sampled twice a month starting from January $1^{\text {st }}$. Oocytes were measured and photographed under a light microscope (Eclipse E400, Nikon). Only females that produce oocytes with more than $400 \mu \mathrm{m}$ in diameter were subjected to hormone injection. Female fish were induced with intramuscular injection of pellet des-Gly 10[D-Ala6]-LHRH-A (Sigma Aldrich) $(100 \mu \mathrm{g} / 1000 \mathrm{~g}$ of body weight) according to Aydin and Okumus (2017).

Females were periodically checked for the sign of ovulation by palpation. Females that ready to spawn were weighed before and after collecting eggs to determine relative fecundity. Eggs were hand stripped into a dry plastic bowl and weighed. Eggs were fertilized with hand stripped milt obtained from two males in seawater (\%o18 salinity) using the wet fertilization technique. Fertilized eggs were sterilized by incubating in PVP iodine solution (100 ppm) for 10 minutes and incubated in cylindrically conical incubation tanks. The number of eggs was estimated by counting a proportion of eggs. Egg diameters were measured under light microscope. The fertilization rate was estimated by sampling during the 2-64 cell stage. The hatching rate was estimated by sampling after hatching according to (Polat et al., 2018).

\section{Sperm Analysis}

For sperm analysis, milts were collected from mature fish with a syringe. Sperm spermatocrit rates were estimated by the microhematocrit technique. For this purpose, milt drawn in microhematocrit tubes were centrifuged at $12000 \mathrm{rpm}$ for 10 minutes to separate the spermatozoa. To determine the sperm concentration, the collected sperm sample was drawn into a dilution pipette and diluted with distilled water (1/100). Sperm suspensions were loaded into a thoma cell counting chamber and counted by hemocytometer method.

Kinetic parameters (Motility, Curve speed, Linear speed, Linearity index, Beat frequency etc.) of the sperm samples were assessed by using a sperm class analyzer (SCA) CASA system with negative phase contrast (Ph-) microscopy (Nikon Eclipse $\mathrm{Cl}$ ). A digital camera attached to the microscope was used to capture images. Sperm samples loaded to chamber slides were activated with addition of seawater with \%o18 salinity. Sperm cell 
tracks were photographed and analyzed. The osmolarity of milt samples was measured with Osmomat 3000 (Gonotec, Berlin). pH-Indicator papers (Merck) were used to measure the $\mathrm{pH}$ of milt samples. The viability duration of spermatozoa was assessed with Leja slide (Leja, Holland).

\section{Statistical analysis}

The normality of data and homogeneity of variances were tested by Shapiro-Wilk and Levene's tests, respectively. The mean values of the parameters were compared using one-way analysis of variance (ANOVA). All statistical analyses were performed using $\mathrm{R}$ ver.4.0.3 (R Core Team, 2020) and significance level was considered as $\mathrm{P}<0.05$.

\section{Results}

Oocyte samples were collected from the MP group on January $20^{\text {th }}$ and from the NP group on April $27^{\text {th }}$. A total of 620 oocytes were sampled from 12 females ( 6 natural photoperiods and 6 manipulated photoperiod). The average oocyte diameters of the females exposed to MP and NP were 399.04.50 $\pm 2.75 \mu \mathrm{m}$ and $401.14 \pm 3.32$ $\mu \mathrm{m}$, respectively and found to be similar (ANOVA, $\left.F_{1,618}=0.237, P=0.627\right)$. The average of oocyte diameters of both groups exposed to MP ( $t(312)=-0.347, P=0.728)$ and $\mathrm{NP}(\mathrm{t}(306)=0.342, \mathrm{P}=0.732)$ were equal to $400 \mu \mathrm{m}$. Moreover, almost $50 \%$ of the sampled oocytes were greater than $400 \mu \mathrm{m}$ in diameter (Figure 3). Thus, 6 females from each group were induced by hormone injection on January $25^{\text {th }}$ (MP group) and on April $28^{\text {th }}$

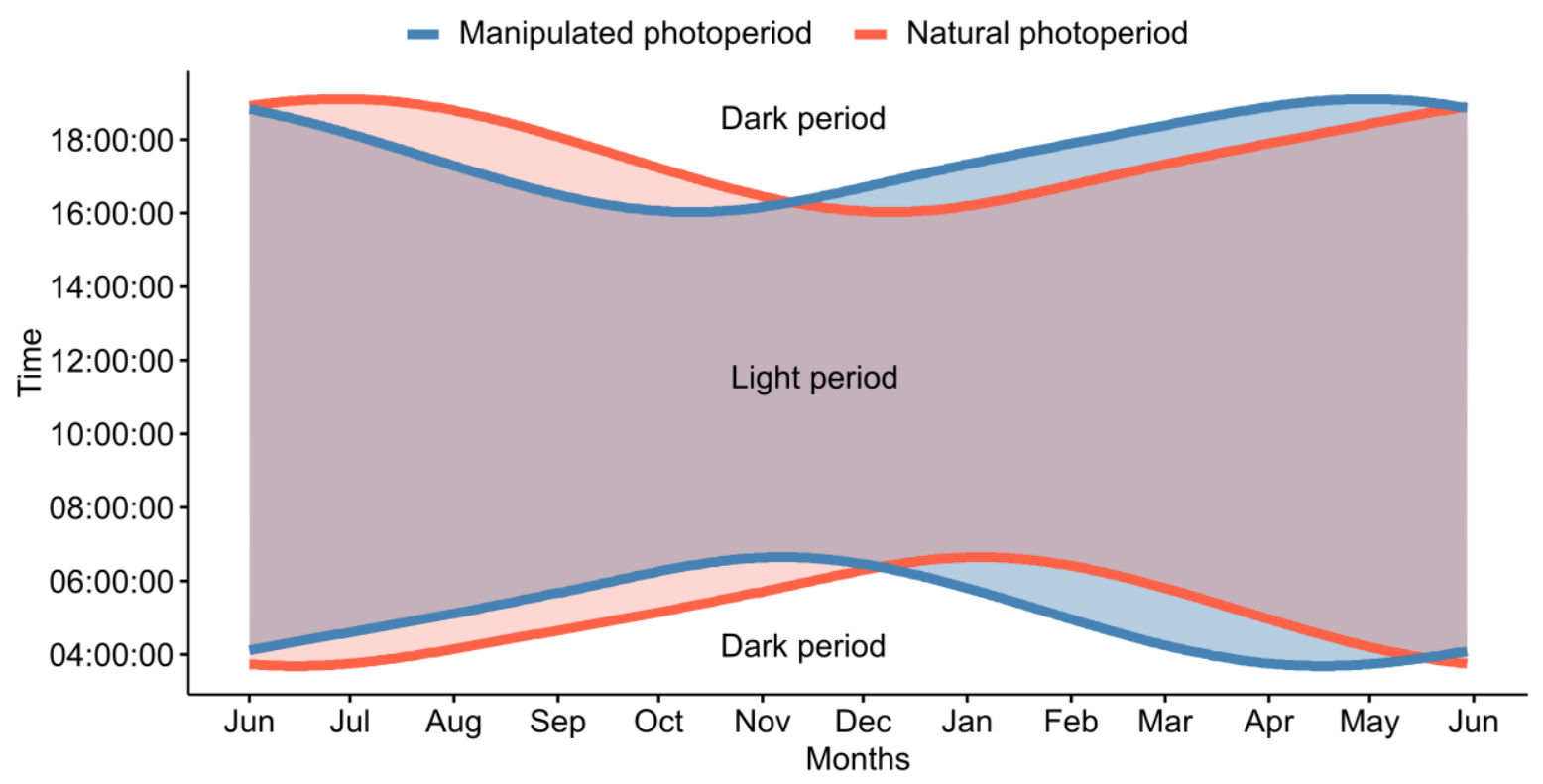

Figure 1. Natural (red) and Manipulated (blue) photoperiod regimes
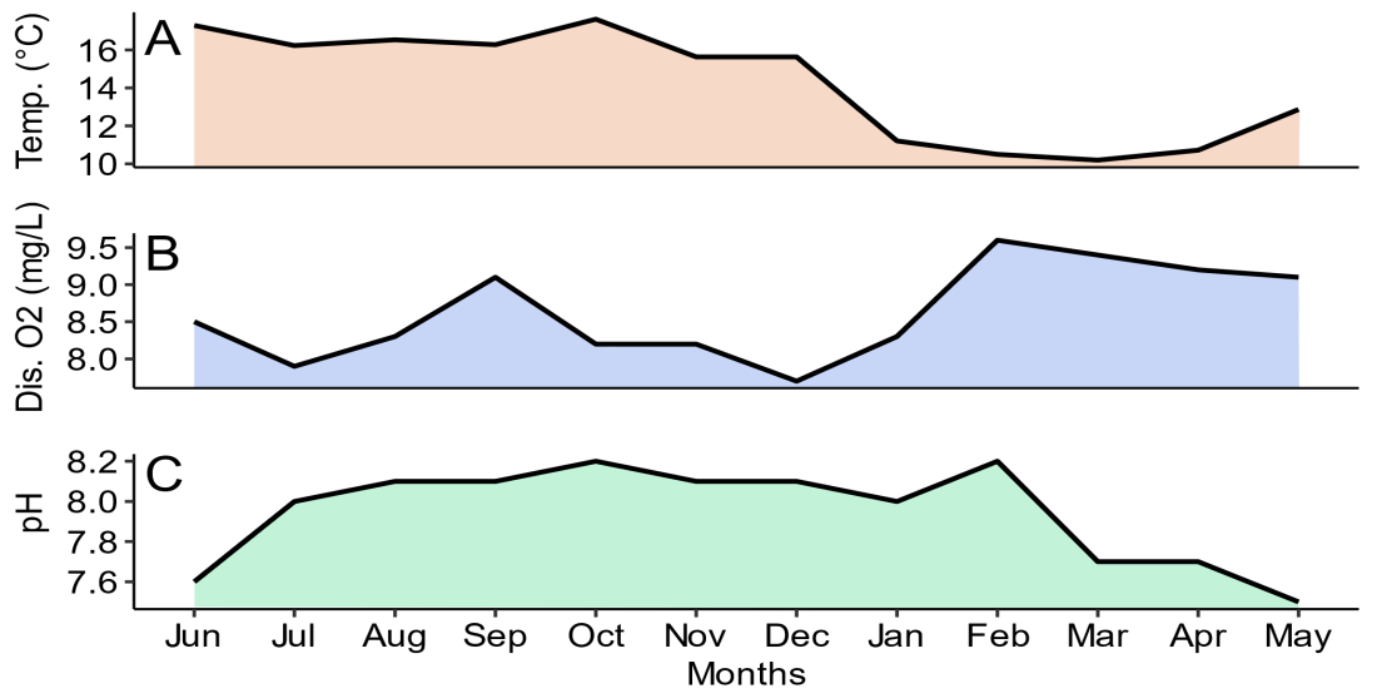

Figure 2. Monthly changes in water temperature (A), dissolved oxygen (B), and pH (C). 
(NP group). Concerning the spawning rhythms, four females in MP group positively responded induction and MP group begin spawning in February $10^{\text {th }}$ (15 days postinduction). Females were stripped 8 to 17 days at $24 \mathrm{~h}$ intervals. Meanwhile, five females in the NP group positively responded to induction and the NP group begin spawning on May $12^{\text {th }}$ (13 days post-induction). Females were stripped 9-17 days at $24 \mathrm{~h}$ intervals.

The average diameters of the stripped eggs of MP and NP groups were $1.22 \pm 0.04 \mathrm{~mm}$ and $1.23 \pm 0.03 \mathrm{~mm}$, respectively. The average fecundity of $\mathrm{MP}$ and NP groups were $389,2410 \pm 309,688$ and $412,0560 \pm 146,808$, respectively. The average relative fecundity of MP and NP groups were $826,850 \pm 56$ and $903,903 \pm 25$, respectively. The average fertilization rate, hatching rate, and abnormal larvae hatching rate of the MP group were $75.92 \pm 2.7 \%, 82.3 \pm 3.1 \%$, and $4.42 \pm 0.06 \%$, respectively. The average fertilization rate, hatching rate, and abnormal larvae hatching rate of the NP group were $78.11 \pm 1.89 \%, 86.37 \pm 2.34 \%$, and $3.02 \pm 0.22$ percent, respectively. The mentioned measurements were tested by one-way ANOVA and no significant differences were determined between the groups (Figure 4).

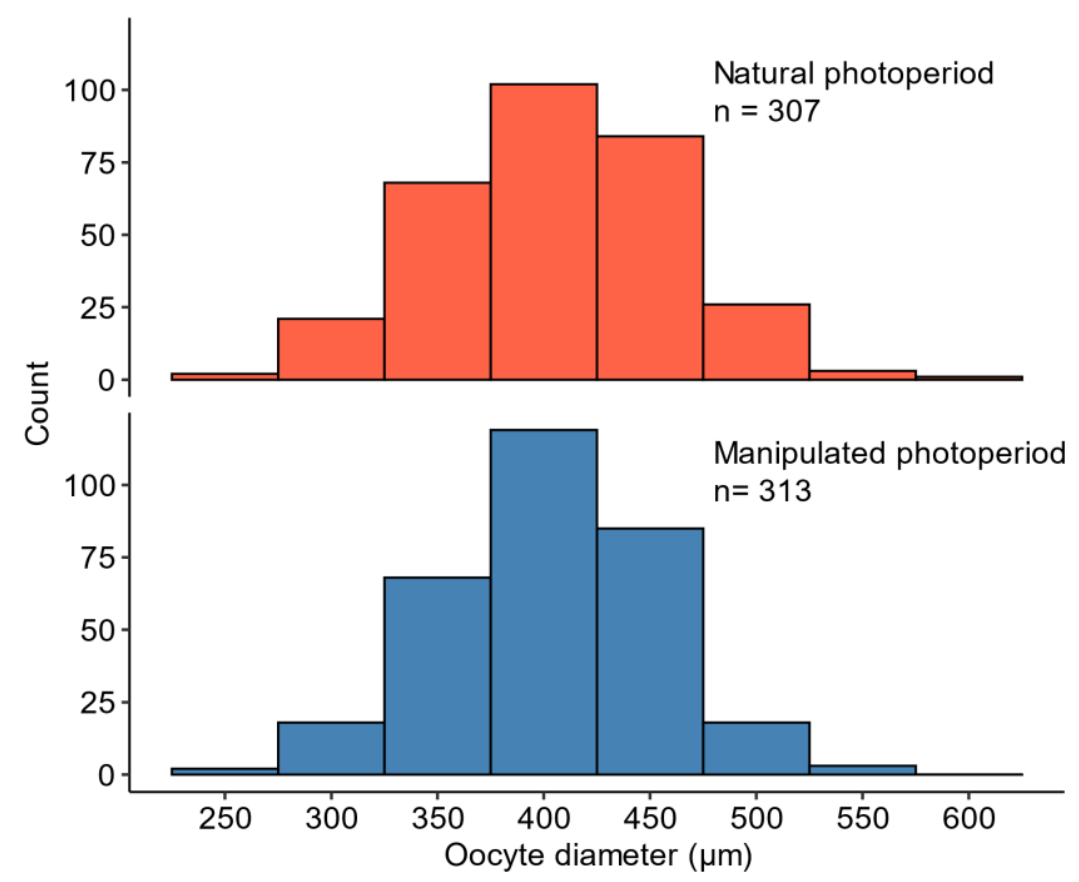

Figure 3. Histogram of the oocytes sampled from the females exposed to NP and MP

Manipulated photoperiod

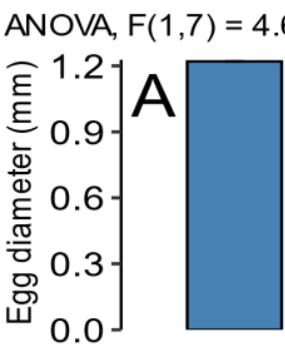

ANOVA, $F(1,7)=0.002, p=0.967$
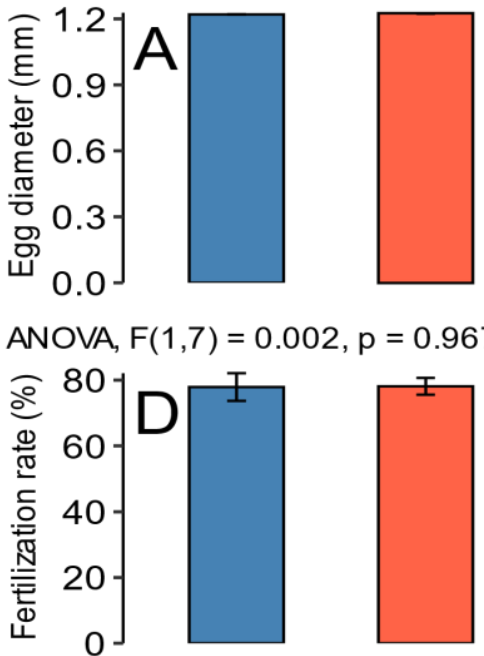

$$
\text { L }
$$
Figure 4. Comparison of egg diameter $(A)$, fecund
larvae hatching rate $(F)$ of the MP and NP groups

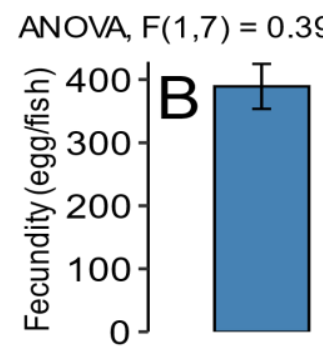

ANOVA, $F(1,7)=1.796, p=0.222$

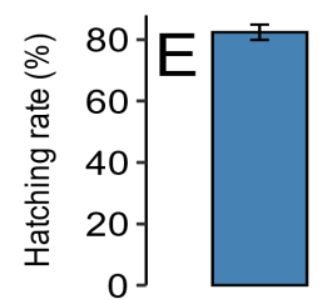

Natural photoperiod 
Milt was successfully obtained from five fish from the MP group and seven fish from the NP group. The average $\mathrm{pH}$ of the milt of MP and NP groups was $7.10 \pm 0.04$ and $7.16 \pm 0.06$, respectively. The average sperm density of MP and NP groups were 2.18 \pm 0.15 $\mathrm{x} 10^{9} / \mathrm{ml}$ and $2.24 \pm 0.10 \times 10^{9} / \mathrm{ml}$, respectively. The average sperm volume of MP and NP groups was $1.92 \pm 0.26 \mathrm{ml}$ and $2.41 \pm 0.17 \mathrm{ml}$, respectively. The average spermatocrit context of MP and NP groups was $41.7 \pm 4.42 \%$ and $41.9 \pm 3.58 \%$, respectively. The average sperm osmolarity of MP and NP groups was 320.00 \pm 2.09 $\mathrm{mOsm} / \mathrm{kg}$ and $317.33 \pm 4.43 \mathrm{mOsm} / \mathrm{kg}$, respectively. There was no statistical difference between the MP and NP groups in terms of the mentioned sperm measurements (Figure 5). Additional and detailed kinetic sperm parameters are given in Table 1.

\section{Discussion}

Positive effects of photoperiod manipulation on maturation have been recorded in several species (Carrillo et al., 1989; Hansen et al., 1992; Macquarrie et al., 1978) including turbot (Imsland et al., 2013; Imsland \& Jonassen, 2003). Imsland and Jonassen (2003) found that maturation in juvenile turbot is related to photoperiod regime and lower maturation was observed in males that exposed to continuous or extended light. Imsland et al (2013) revealed that continuous light delays maturity in juvenile turbot. While there are handful of studies on the effect of photoperiod manipulation on maturity, the effect of photoperiod manipulation on spawning season and spawning performance of turbot is unknown. This effect

Manipulated photoperiod $\bigcirc$ Natural photoperiod
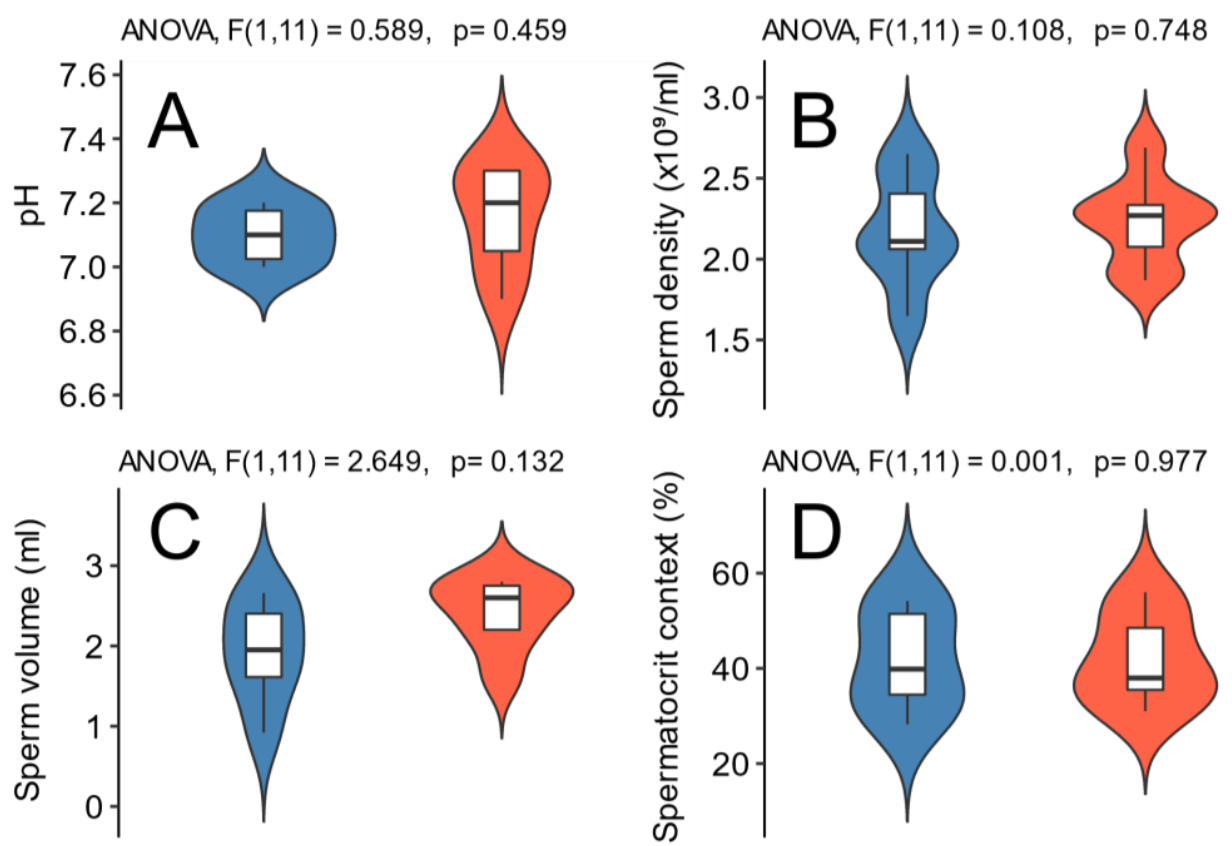

Figure 5. Comparison of sperm quality parameters between manipulated photoperiod $(n=5)$ and natural photoperiod $(n=7)$ groups. A-Sperm pH, B-Sperm density, C-Sperm volume, and D-Spermatocrit context.

Table 1. Kinetic sperm parameters of MP and NP groups

\begin{tabular}{lcccccccc}
\hline Fish & $\begin{array}{c}\text { MOT } \\
(\%)\end{array}$ & $\begin{array}{c}\text { VCL } \\
\left(\mu \mathrm{m} \mathrm{s}^{-1}\right)\end{array}$ & $\begin{array}{c}\text { VAP } \\
\left(\mu \mathrm{m} \mathrm{s}^{-1}\right)\end{array}$ & $\begin{array}{c}\text { VSL } \\
\left(\mu \mathrm{m} \mathrm{s}^{-1}\right)\end{array}$ & LIN (\%) & STR (\%) & ALH $(\mu \mathrm{m})$ & BCF (Hz) \\
\hline MP-M1 & 56.38 & 100,66 & 84,43 & 58,15 & 72,1 & 74,69 & 3,96 & 4,55 \\
MP-M2 & 71.66 & 61,66 & 44,65 & 41,82 & 61,40 & 78,40 & 2,88 & 5,02 \\
MP-M3 & 73.04 & 101,41 & 75,51 & 60,12 & 59,29 & 79,62 & 5,59 & 4,28 \\
MP-M5 & 86,68 & 73,98 & 53,34 & 37,89 & 56,63 & 84,80 & 3,41 & 7,51 \\
MP-M6 & 95,07 & 113,34 & 77,86 & 72,57 & 51,31 & 85,95 & 5,93 & 2,92 \\
NP-M1 & 80.69 & 61.42 & 49.12 & 39.45 & 47.62 & 62.03 & 1.85 & 5.61 \\
NP-M2 & 95.37 & 80.71 & 56.24 & 33.86 & 39.58 & 56.08 & 3.08 & 4.53 \\
NP-M3 & 78.64 & 66.88 & 50.82 & 32.76 & 39.86 & 55.35 & 2.47 & 3.55 \\
NP-M4 & 74.70 & 70.07 & 48.68 & 30.29 & 36.09 & 53.35 & 2.69 & 3.88 \\
NP-M6 & 83.71 & 92.87 & 74.29 & 52.29 & 58.35 & 71.70 & 3.22 & 6.93 \\
NP-M7 & 88.71 & 99.03 & 77.22 & 60.09 & 62.36 & 81.18 & 4.95 & 5.22 \\
\hline
\end{tabular}

MOT-Motility, VCL-Curve speed, VSL-Linear speed, VAP-Average speed, LIN-Linearity index, STR-Straightness index, ALH-Amplitude lateral head, BCF-Beat frequency. 
of photoperiod manipulation on spawning season and spawning performance of turbot is evaluated for the first time in the study.

Turbot spawn in early summer (between April to June) in the Black Sea $\left(41^{\circ} \mathrm{N}\right)$. In photoperiod manipulated group, fish spawned almost three months earlier compared to the natural photoperiod group which indicates the importance of the photoperiod on spawning season. The natural photoperiod group, that considered as the control group, spawned in May, which is reflecting the natural trend in the Black Sea.

Six out of 7 females from each group produced oocytes with the desired diameter $(\geq 400 \mu \mathrm{m})$. According to Çiftci et. al. (2002) females with an average oocyte diameter of $400 \mu \mathrm{m}$ can be used for spawning procedures with hormone injection. Four out of six females from MP and five out of 6 females from NP positively responded to ovulation induction and used in spawning. Nonresponse to ovulation induction among broodstock is a common phenomenon in turbot (Mugnier et al., 2000). Individual differences between groups, rather than photoperiod manipulation could be the main result behind the differences in the number of positively induced individuals. The stripped egg size of the groups was similar. Egg size similarity between hormone induced and control groups was previously reported (Mugnier et al., 2000).

Mcevoy and Mcevoy (1991) reported that the mean egg diameters of turbot reduce with each batch under constant water temperature. Bromley et al. (1986) found a negative relationship between egg diameter and water temperature at the time of spawning. However, in this study, almost identical average egg sizes were recorded for both NP and MP groups. Shortened spawning duration and water temperature appeared to be not related to the egg size. However, it is worth mentioning that female fish used in this study did not subject to hormone induction in the previous spawning season.

Usage of outdoor tanks and sea cages in initial trials of turbot culture has been suppressed for being not viable. Intensive rearing conditions under a controlled environment are being applied in both the grow-out and on-growing phase of turbot. Indoor facilities with heated water and mostly with re-circulation systems are now in use in most of the turbot farms (Peron-Le, 2002). Photoperiod manipulation in indoor facilities is easier and applicable. Thus, the result of this study may have implications in the turbot aquaculture industry.

\section{Conclusion}

The effect of the manipulated photoperiod on the spawning time, egg, and sperm production of turbot S. maximus were assessed. Previous studies reported that the manipulated photoperiod has positive effect on growth and maturity of turbot. This study reveals that spawning time of the turbot can be pushed forward by manipulating the natural daylength. The fish exposed to manipulated photoperiod exhibited similar reproductive and hatchery performance with the ones held in natural photoperiod. To this respect, the manipulated photoperiod can be used for early hatchery rearing in the production process. Nevertheless, comprehensive research is needed to understand effect of photoperiod along with different light intensities on the hatchery performance, embryonic and pre-larval development, and metamorphosis.

\section{Ethical Statement}

Not aplicable

\section{Funding information}

This study was funded by the Agricultural Research and Policy General Directorate of the Ministry of Agriculture and Forestry of the Republic of Turkey. (Grant Number: TAGEM/HAYSUD/2014/A11/ P-01/1).

\section{Author Contributions}

Hamza POLAT: Conceptualization, project administration, funding acquisition, methodology, investigation. Rafet Cagri OZTURK: Formal analysis, writing-original draft. Yahya TERZI: Formal analysis, visualization, writing-original draft. Ilhan AYDIN: Conceptualization, supervision. Ercan KUCUK: Conceptualization, supervision.

\section{Conflict of interest}

The authors declare that there are no conflicts of interest regarding the publication of this article.

\section{Acknowledgement}

The authors thank the personnel of the aquaculture unit of Central Fisheries Research Institute for their contribution and technical assistance during the experiments.

\section{References}

Abdollahpour, H., Falahatkar, B., \& Lawrence, C. (2020). The effect of photoperiod on growth and spawning performance of zebrafish, Danio rerio. Aquaculture Reports, 17, 100295. https://doi.org/10.1016/j.aqrep.2020.100295

Akhoundian, M., Salamat, N., Savari, A., Movahedinia, A., \& Salari, M. A. (2020). Influence of photoperiod and temperature manipulation on gonadal development and spawning in Caspian roach (Rutilus rutilus caspicus ): Implications for artificial propagation. Aquaculture Research, 51(4), 1623-1642. https://doi.org/10.1111/are.14509

Altinok, I., Ozturk, R. C., Capkin, E., \& Kalayci, G. (2020). Experimental crossbreeding reveals variation in growth among brown trout (Salmo trutta) strains and their reciprocal crossbreeds. Aquaculture, 521, 734983. 
Aydin, I., Polat, H., \& Sahin, T. (2020). Reproductive performance of wild and hatchery-reared black sea turbot, psetta maxima, in the southern black sea coast. Turkish Journal of Fisheries and Aquatic Sciences, 20(5), 351-357. https://doi.org/10.4194/1303-2712-v20_5_03

Aydin, I., \& Şahin, T. (2011). Reproductive performance of turbot (Psetta maxima) in the southeastern black sea. Turkish Journal of Zoology, 35(1), 109-113. https://doi.org/10.3906/zoo-0905-26

Aydın, i., \& Okumuş, i. (2017). Effects of triploid induction to the early cleavage patterns of black sea turbot (Psetta maxima) embryos. Genetics of Aquatic Organisms, 1(1), 15-20. https://doi.org/10.4194/2459-1831-v1_1_03

Bromage, N., Porter, M., \& Randall, C. (2001). The environmental regulation of maturation in farmed finfish with special reference to the role of photoperiod and melatonin. In Aquaculture, 197(4), 63-98. https://doi.org/10.1016/S0044-8486(01)00583-X

Bromage, N. R., Elliott, J. A. K., Springate, J. R. C., \& Whitehead, C. (1984). The effects of constant photoperiods on the timing of spawning in the rainbow trout. Aquaculture, 43(3), 213-223. https://doi.org/10.1016/0044-8486(84)90023-1

Bromley, P. J., Sykes, P. A., \& Howell, B. R. (1986). Egg production of turbot (Scophthalmus maximus L.) spawning in tank conditions. Aquaculture, 53(3-4), 287293. https://doi.org/10.1016/0044-8486(86)90359-5

Caputo, V., Candi, G., Colella, S., \& Arneri, E. (2001). Reproductive biology of turbot (Psetta maxima) and brill (Scophthalmus rhombus) (Teleostei, Pleuronectiformes) in the Adriatic Sea. Italian Journal of Zoology, 68(2), 107113. https://doi.org/10.1080/11250000109356393

Carrillo, M., Bromage, N., Zanuy, S., Serrano, R., \& Prat, F. (1989). The effect of modifications in photoperiod on spawning time, ovarian development and egg quality in the sea bass (Dicentrarchus labrax L.). Aquaculture, 81, 351-365. https://doi.org/10.1016/0044-8486(89)90159-2

Çiftci, Y., Üstündağ, C., Erteken, A., Özongun, M., Ceylan, B., Haşimoğlu A., Güneş, E., Yoseda, K., Sakamoto, F., Nezaki, G., and Hara, S. (2002). Manual for the Seed Production of Turbot, Psetta maxima in the Black Sea, 53 (9).

Firidin, S., Ozturk, R. C., Alemdag, M., Eroglu, O., Terzi, Y., Kutlu, I., Duzgunes, Z. D., Cakmak, E., \& Aydin, I. (2020). Population Genetic Structure of Turbot (Scophthalmus maximus L., 1758) in the Black Sea. Journal of Fish Biology, 97(4), 1154-1164. https://doi.org/10.1111/jfb.14487

Hansen, T., Stefansson, S., \& Taramger, G. L. (1992). Growth and sexual maturation in Atlantic salmon, Salmon salar L., reared in sea cages at two different light regimes. Aquaculture Research, 23(3), 275-280. https://doi.org/10.1111/j.1365-2109.1992.tb00770.x

Imsland, A. K., Folkvord, A., Jonsdottir, Ö. D. B., \& Stefansson, S. O. (1997). Effects of exposure to extended photoperiods during the first winter on long-term growth and age at first maturity in turbot (Scophthalmus maximus). Aquaculture, 159, 125-141.

Imsland, Albert K., Folkvord, A., \& Stefansson, S. O. (1995). Growth, oxygen consumption and activity of juvenile turbot (Scophthalmus maximus L.) reared under different temperatures and photoperiods. Netherlands Journal of Sea Research, 34(1-3), 149-159.

https://doi.org/10.1016/0077-7579(95)90023-3

Imsland, Albert K., Gunnarsson, S., Roth, B., Foss, A., Le Deuff, S., Norberg, B., Thorarensen, H., \& Helming, T. (2013). Long-term effect of photoperiod manipulation on growth, maturation and flesh quality in turbot. Aquaculture, 416-417, 152-160.

https://doi.org/10.1016/j.aquaculture.2013.09.005

Imsland, Albert K., \& Jonassen, T. M. (2003). Growth and age at first maturity in turbot and halibut reared under different photoperiods. In Aquaculture International, 11(5), 463-475.

https://doi.org/10.1023/B:AQUI.0000004191.43885.b2

Jeannine Peron-Le, R. (2002). Turbot (Scophthalmus maximus) Grow-out in Europe: Practices, Results, and Prospects. Turkish Journal of Fisheries and Aquatic Sciences, 2(1), 29-39.

Jones, A. (1974). Sexual Maturity, Fecundity and Growth of the Turbot Scophthalmus Maximus L. Journal of the Marine Biological Association of the United Kingdom, 54(1), 109-125. https://doi.org/10.1017/S0025315400022104

Kilincceker, O., \& Kurt, S. (2010). Stocking density and photoperiod manipulation in relation to estradiol profile to enhance spawning activity in female Nile tilapia. Turkish Journal of Fisheries and Aquatic Sciences, 10(4), 471-476. https://doi.org/10.4194/trjfas.2010.0405

Macquarrie, D. W., Markert, J. R., \& Vanstone, W. E. (1978). Photoperiod induced off-season spawning of coho salmon (Oncorhynchus kisutch). Annales de Biologie Animale, Biochimie, Biophysique, 18(4), 1051-1058.

Mcevoy, L. A., \& Mcevoy, J. (1991). Size Fluctuation in The Eggs and Newly Hatched Larvae of Captive Turbot (Scophthalmus Maximus). Journal of the Marine Biological Association of the United Kingdom, 71(3), 679-690. https://doi.org/10.1017/S0025315400053236

Mugnier, C., Guennoc, M., Lebegue, E., Fostier, A., \& Breton, B. (2000). Induction and synchronisation of spawning in cultivated turbot (Scophthalmus maximus L.) broodstock by implantation of a sustained-release $\mathrm{GnRH}$-a pellet. Aquaculture, 181(3-4), 241-255. https://doi.org/10.1016/S0044-8486(99)00234-3

Oliveira, C., Mananos, E., Ramos, J., \& JSanchez-Vazquez, F. J. (2011). Impact of photoperiod manipulation on day/night changes in melatonin, sex steroids and vitellogenin plasma levels and spawning rhythms in Senegal sole, Solea senegalensis. Comparative Biochemistry and Physiology. Part A, Molecular \& Integrative Physiology, 159(3), 291-295.

Polat, H., Özen, M. R., \& Keskin, S. Y. (2018). The embryonic development of black sea turbot (Psetta maxima Linnaeus, 1758) eggs in different incubation temperatures and salinities. Turkish Journal of Fisheries and Aquatic Sciences, 18(3), 475-482. https://doi.org/10.4194/1303-2712-v18_3_13

R Core Team. (2020). R: A Language and Environment for Statistical Computing.

Turker, A. (2005). Effects of photoperiod on growth and feed utilization of juvenile Black Sea turbot (Psetta maeotica). In Israeli Journal of Aquaculture - Bamidgeh, 57 (3), 156163. https://doi.org/10.46989/001c.20413 